\title{
Laura N. Gasaway: Defining an Expert
}

\author{
by Lea Ann Robertson
}

\begin{abstract}
Introduction
The issues surrounding copyright and intellectual property law have escalated greatly in the last several years. Advancements in computer technology have forced a progression of interest in these issues and nowhere else does this interest appear more prevalent than in the fields of information science and law. No longer will the old laws suffice. Technology has been allowed to progress without limitations, and therefore, there has been a "failure of copyright law to keep pace with the needs of authorship." ${ }^{1}$ It is now the responsibility of lawmakers, lawyers, and information experts to construct a system that will protect all interested parties.
\end{abstract}

The subject of this research, Laura (Lolly) N. Gasaway, has been a notable presence in the area of copyright law for over twenty years. She has been the director of the law library and a professor of law for the University of North Carolina at Chapel Hill (UNC) since 1985. It was about this time that Gasaway began honing her skills in the areas of intellectual property and copyright law, skills that have brought her recognition by her peers and respect from both the legal and information science communities.

The American Library Association refers to Gasaway as "an expert in copyright law." ${ }^{2}$ How does one become an expert in copyright law? What is an expert? The Merriam-Webster Online dictionary defines an expert as "having, involving, or displaying special skill or knowledge derived from training or experience."3

What aspect of her accomplishments makes Lolly Gasaway an "expert"? Is it her advanced education in law? Is it her publication in non-academic literature? Is it based solely on her publication in scholarly journals? Is it that she has been asked to represent important associations such as the Association of American Universities, the American Council on Education, and the National Association of State Universities and Land-Grant Colleges as a proponent of copyright law changes in an effort to advance the development of distance education through digital technologies? Is it her resume of speaking engagements over the last several years? Is it her experience as a lawyer since 1973 specializing in the areas of copyright law, copyright and technology, and cyberspace issues? It would obviously be impossible here to approach all of these issues that make Lolly Gasaway the expert that she is touted to be. As both an attorney and a law librarian, does Gasaway lean more towards writing for law journals or those dedicated to information science? Or are her topics uniquely the same for both fields of study? Are there particular aspects of copyright in which Lolly Gasaway has a more keen interest? Over time, has she concentrated her writings more on issues of copyright?

This study is bibliometric in design. This type of research is essentially a quantitative analysis of publications for the purpose of ascertaining specific kinds of phenomena. ${ }^{4}$ It analyzes a limited number of publications in the fields of law and information science written by Laura N. Gasaway.

\section{Statement of the Problem}

The purpose of this study is to examine the authorship patterns of a limited list of publications by Laura N. Gasaway. The publications reviewed and analyzed are those listed within the Faculty Publications section of the UNC Web site. ${ }^{5}$ More particularly, this study (a) identifies the number of publications of Laura Gasaway in scholarly journals, (b) identifies the number of publications of Laura Gasaway in non-scholarly journals, (c) indicates whether this author publishes in more law-related journals than in those associated with the field of library and information science, and (d) identifies Gasaway's trend of publishing more on the topic of copyright with the passage of time.

\section{Hypotheses}

H1: $\quad$ Gasaway publishes two or three scholarly articles per year.

H2: $\quad$ Gasaway has been published in more information science publications than law journals.

H3: $\quad$ Over time, Gasaway’s publications have focused more on copyright issues.

\section{Delimitations}

This study is limited to Gasaway's publications itemized on the official Web site of the University of North Carolina at Chapel Hill (UNC). Items not appearing on this list were not considered for analysis.

\section{Definitions}

Bibliometric research - the study of specific aspects of literature, including authors, citations, and content.

Copyright - the exclusive legal rights to reproduce, publish, and sell the matter and form.

UNC - University of North Carolina at Chapel Hill. 


\section{Assumptions}

The time frame for the journal articles examined in this study is sufficient to indicate author publication patterns. It is assumed that the publication information contained on the UNC Web site, and examined in this study, is accurate and complete.

\section{Importance of the Study}

This investigation of the publication patterns of Laura N. Gasaway provides an important look into the progression of issues in copyright law that affects information scientists and their work. A review of previous literature indicates that the quantity of publications is not an appropriate measurement of quality or expert status. This study analyzes past submissions that may indicate the publishing patterns of Laura N. Gasaway.

\section{Review of Related Literature}

A thorough search of scholarly library and information science of literature retrieved no study of publishing patterns of author Laura $\mathrm{N}$. Gasaway. Therefore, a literature review was performed focusing on the analyses of authorship publication patterns in scholarly journals. Publication pattern studies are quantitative in nature and are defined within the field of bibliometric research. This type of research is employed by library and information scholars to illustrate publication patterns within a given field of study or a certain body of literature.

This literature review includes studies with similar methodologies, yet the greatest part of prior authorship research has not concentrated on one particular author but on a body of authors in a field. This type of examination most often follows one of the three established laws of bibliometric research. Lotka's Law focuses on the contributions of authors and generally states that out of all the authors in a given field, few of them will have more than one publication. ${ }^{6}$ According to Lotka's Law of scientific productivity, only six percent of the authors in a field will produce more than ten articles. ${ }^{7}$ In his article "Of Making Many Books There is No End: Bibliometrics and Libraries," William Potter says Lotka's Law can generally be accurate only when applied to a large body of literature over an extended period of time. ${ }^{8}$

In his April 2000 study A Highly Visible Scientist - Jack Meadows, author J. Michael Brittain analyzes the publication patterns of scientist Jack Meadows." The articles studied span Lotka's required "large body of literature over an extended period of time." The study period covers forty years in over 250 different journals, and all have been cited in a large range of disciplines and sub-disciplines, including library and information science and bibliometrics. Likewise, this study of Laura Gasaway's works spans a number of years and publication in several different journals consisting of varying subject matter. These include (1) the number of publications and citations, (2) the number of citations received over time, and (3) the number of citations received over disciplines. The method of analysis included listing the reasons for citing Meadows' works and nineteen of these citations were reviewed further to determine a classification scheme for the citing articles. The overall conclusion was that most of the citations to Jack Meadows' work were for substantiating concepts and laws in bibliometrics and not for lending credit to Meadows for new, advanced discoveries.

Another study reviewed publication patterns within a single scholarly journal, Journal of the American Society for Information Science, for changing trends in authorship, co-authorship, frequency of authorship, gender, geography, and institutional affiliation. ${ }^{10}$ The sample taken in this particular study included the entire publication history of this journal; however, many researchers limit their reports to include limited dates of publication.

"Article Content and Authorship Trends in The Reading Teacher, 1948-1991" reported the results of a study of authorship patterns of publication. ${ }^{11}$ Calculated was the total number of authors published during the reported time frame, which authors published most frequently, and the subject matter of those papers published. It was determined that of the four highest published authors in the subject journal, only one author had printed materials in every eleven-volume period reviewed. These top four writers composed their material on a variety of topics rather than concentrating on one or two subjects.

\section{Methodology}

The research methodology is structured to gather, organize and analyze the data relevant to the objectives of the study. It begins with a review of the works authored by Laura N. Gasaway listed on the Web site of UNC, her institutional affiliation. Of the research located on this webpage, every paper has been categorized into one of the following: (1) scholarly journal publication, (2) non-scholarly journal publication, (3) book, (4) book chapter, or (5) undetermined. From the total number of works, the frequency of publication, number of law journal articles written, and the number of information science articles written were tabulated for the purpose of mapping the author's progression in focusing on copyright issues.

The information culled was placed into corresponding columns within a Microsoft Word table. Once all data were entered, calculations were performed and graphs were prepared that accurately represents Laura N. Gasaway's publication patterns. Graphs were prepared to report the progression or digression of copyright influence on the topics covered in her publications.

\section{Results}

As both a licensed attorney and an experienced law librarian, Laura Gasaway's research appears in journals dedicated to the practice of law, as well as journals of library and information science. For the purposes of this research, only those articles located on the faculty pages of the University of North Carolina at Chapel Hill Web site were taken into account. 
According to the Faculty Publications page for the University of North Carolina - Chapel Hill (See Exhibit A), Laura Gasaway has published a total of 75 articles, books, and book chapters on subjects ranging from gender studies to analyses of Circuit Court opinions. Of that total, 39 were found to be articles published within scholarly journals, 14 articles in non-scholarly journals, six books, and 12 book chapters. It should also be noted that the publication source for eight of the total number were categorized as "undetermined."

One of the hypotheses addressed in this research was whether Laura Gasaway has been published in more information science publications or law journals. From the attached Exhibit A, a total of 69 published articles and book chapters was counted. As specified above, eight of these articles and book chapters were tagged "undetermined" and were eliminated from this calculation. Of the 61 remaining articles and book chapters, 23 works were published in law-related journals, and 38 works were published in journals dedicated to library and information science. This hypothesis was supported by the data.

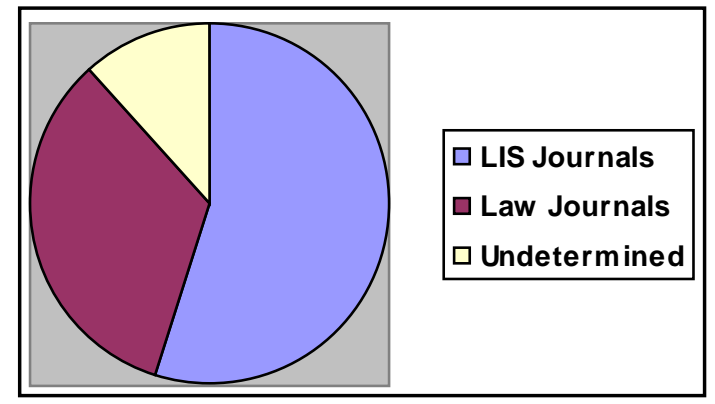

The hypothesis that Gasaway publishes an average of two or three scholarly articles per year was not supported by the data. Half her career was spent publishing more than two or three articles per year. The first publication reflected on the subject list was in 1972, just one year before her graduation from law school at the University of Houston, and her last publication was in 2003. Excluding books, her career from the years 1972 through 2003 has included the publication of 32 articles. Only six of those years have gone without publication (1974, $1975,1980,1985,1987$, and 1988). Nine years she published one article, five years two articles, five years three articles, three years four articles, two years five articles, one year six articles, and one year seven articles.

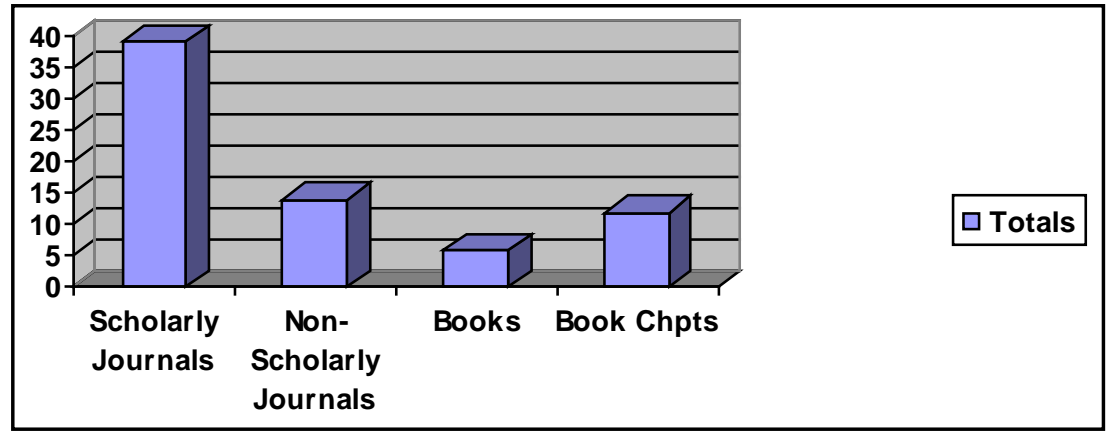

Hypothesis 3 is supported by the data. Over time, Gasaway's publications have become more focused on copyright issues. In 1983, she published her first works on copyright, approximately ten years after graduating from law school. For the next ten years, only nine of her research projects included topics other than copyright and intellectual property. After 1993, Gasaway's writings are made up almost entirely of copyright and open access issues.

\section{Conclusion}

Is the total number of publications in one's career an accurate measure of success? Dr. Melanie Norton in her book, Introductory Concepts in Information Science states, "How many articles an author has published yields no information about the quality of those articles." ${ }^{12}$ In $A$ Highly Visible Scientist - Jack Meadows," author J. Michael Brittain explains that for years North American institutions of higher learning used the total number of publications and/or citations as a performance indicator. He also states, however, that "frequency of citation does not indicate the reasons for citation or influence on other researchers and writers." 13 That being said, the jury may still be out on whether or not the number of publications and frequency of citations is a proper indicator of success, but research has not indicated whether or not frequency of publication is an accurate measure of expert status.

Laura Gasaway has, through her work and research, obtained a high level of recognition by her peers and earned respect from both the legal and information science communities as an expert in the field of copyright law and intellectual property. She is frequently hired as a copyright consultant for projects such as the Mississippi Digital Library Program. 